\title{
FABRICATION, CHARECTERIZATION AND DEVELOPMENT OF HIGH DAMPING MATERIALS FOR NAVAL APPLICATIONS
}

\author{
Raja Surya Nukala ${ }^{1}$, J. Ajay ${ }^{2}$ \\ ${ }^{1}$ M.Tech Scholar, Dept. of Mechanical Engineering, L.I.T.A.M, Andhra Pradesh, India \\ ${ }^{2}$ Assistant Professor, Dept. of Mechanical Engineering, L.I.T.A.M, Andhra Pradesh, India
}

\begin{abstract}
Aluminum matrix composites are early inventions during 60's. Presently these are used as railroad equipment and aerospace components. Their application has shown no further growth during the last decade due to lack of toughness. The noncompatibility between the matrix and the reinforcement and lack of good interface among these led to the reduced ductility levels. The limited solubility leads to the alloy formation passing solid solution strengthening while the un dissolved particles help achieving dispersion strengthening. Instead of taking ceramic particulates as reinforcements, metallic reinforcements were dispersed in aluminium matrix. Damping characteristics were calculated for the alloy and composites. Suitable heat treatment enhances the properties of the composite further. The expected mechanical properties will be higher than the regular alloys, which can be useful for various components in naval applications where high damping is required.
\end{abstract}

Keywords: Dispersion Strengthening, Damping.

$* * *$

\section{INTRODUCTION}

Aluminium Metal Matrix Composites (MMCs), inventions during early 60 's, are composed of basically a metallic matrix reinforced with generally ceramics. MMCs exhibit a combination of metallic (toughness and formability) and ceramic (high strength and hardness with load bearing capacity) properties. These are tailor made materials to suit to particular requirements like reduction in density or improvement in stiffness, yield strength, ultimate tensile strength, which can be translated to improved specific properties. Depending on the application, a wide range of composites with different combinations of matrix materials and dispersoids are being produced. Initial investigations were made with process development using fibre reinforcement. Anisotropy, expensive fabrication cost and restricted secondary processing has led to the use of short fibre / particulate / whisker reinforced composites. The combination of good transverse properties, low cost high workability and significant increase in performance over unreinforced alloys are the commercially attractive features of these discontinuous reinforced composites. Compared to dispersion strengthened systems, particulate reinforced composites contain coarse size reinforcement $(1-100 \mu \mathrm{m})$ in relatively high weight fractions (1-30\%). In particulate composites, both matrix and reinforcement bear substantial load. In addition, matrix strength as affected by precipitation and dislocation strengthening plays an important role in the load bearing capacity of these composites. Metal matrix composites reinforced with ceramic particles are widely used due to their high specific modulus, strength and wear resistance.

\section{LITERATURE}

There are some limitations associated with metal- matrix composites, when ceramic particulates were added as reinforcement, due to improper bonding between matrix and reinforcement, many researchers were identified those problems, Sethi [1] reported that by incorporating ceramic particles in A356 matrix results in weakening of the interfacial bonding and eventually resulting in the pull-out of the $\mathrm{SiC}$ particles because of the lattice straining in the surrounding areas of the particles, there will be a reduction in the extent of plastic deformation that these areas can undergo, which will make them more susceptible to cracking. These cracks will result in the removal of the matrix from adjacent areas of the particles, thereby decreasing the strength of interfacial bond. These fractured particles must also become detached from the matrix. In both the above cases, the strength of the bond between the matrix and the particle is expected to play a critical role in determining wear. E. Gikunoo [2] reported that the presence of stress relieving cracks reaffirms the brittle nature of A535 alloy. Also, increasing the flyash reinforcement leads to a more brittle material. Particle debonding and particle fracture are therefore the main damage mechanisms observed in these MMCs under any mechanical loading. Lloyd D.J et al. [3] studied the effect of particle induced damage in MMCs, with MMCs reinforced by particles with a size greater than $10 \mu \mathrm{m}$, the dominant damage mechanism was cracking of particle and that the particle - matrix interface appeared to have little effect on the overall damage fracture behaviour. Chawla et al. [4] showed that in 2080/SiCp composites with volume fractions ranging from 10 to $30 \mathrm{vol}$. \%, particle cracking was observed above an average particle size of $20 \mu \mathrm{m}$. Also, they showed that fracturing of the particles during extrusion is extremely detrimental to the tensile and fatigue properties of the 
composite, since fractured particles do not carry any load and act as defects that contribute to localization of strain in the composite.

\section{SELECTION OF MATERIALS}

\subsection{Matrix Material}

Aluminium 356 is a binary alloy with $6.5 \% \mathrm{Si}$ and small amounts of $\mathrm{Cu}$, and other common elements. This alloy has a greater importance in engineering industries, as it exhibit high strength to weight ratio, high wear resistance, low density, low coefficient of thermal expansion etc. Silicon imparts high fluidity and low shrinkage, which result in good castability, weldability. Presence of high hard silicon particles, improve wear resistance. The Al-Si system, has a eutectic reaction at $577^{\circ} \mathrm{C}$ and a eutectic composition of 12.6 $w t \%$. As aluminum and silicon solidify in different structures, respectively face centered cubic (FCC) and diamond cubic, two solid phases, $\alpha$ and $\beta$ are produced. At high temperature, the hypoeutectic alloy forms a rich aluminum $\alpha$ - phase solid.

\subsection{Reinforcement Material}

A series of $\mathrm{Al}-\mathrm{Cu}$ binary and $\mathrm{Al}-\mathrm{Cu}-\mathrm{Mg}$ ternary alloys were produced with copper ranged from 10 to $25 \%$ by weight for binary alloys $(\mathrm{Al}-15 \mathrm{Cu}$ and $\mathrm{Al}-25 \mathrm{Cu}) ; 15 \% \mathrm{Mg}$ and $25 \% \mathrm{Mg}$ by weight for ternary alloys (Al-10Cu-15Mg, Al-15Cu$25 \mathrm{Mg}, \mathrm{Al}-25 \mathrm{Cu}-15 \mathrm{Mg}, \mathrm{Al}-25 \mathrm{Cu}-25 \mathrm{Mg}$ ). Figure 1, Shows the microstructure of alloy.

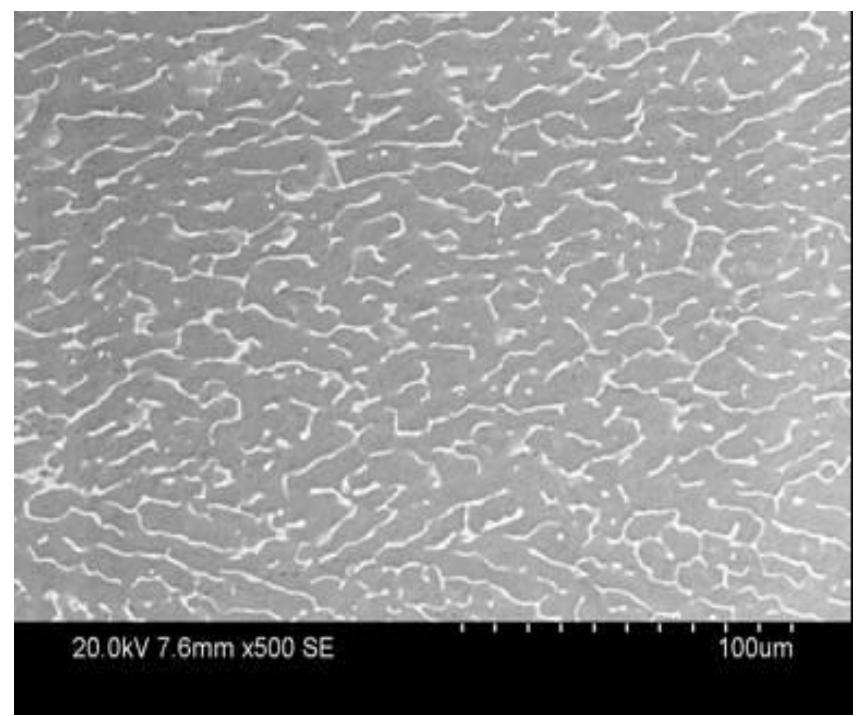

Fig 1 SEM of Reinforcing alloy

Hardness values were checked for each binary and ternary alloys and based on hardness and density $\mathrm{Al}-25 \mathrm{Cu}-25 \mathrm{Mg}$ alloy was choosen as reinforcing material. Alloy powders are produced by different techniques depending on the application involved. In the present investigation, $\mathrm{Al}-\mathrm{Cu}-\mathrm{Mg}$ alloy powders were produced by filing techniques, where, fingers rotating on a lathe, were filed with speeds of rotation ranging between 600, 580 and $190 \mathrm{rpm}$. Finer powders were obtained at high speed and with finer files shown in figure2

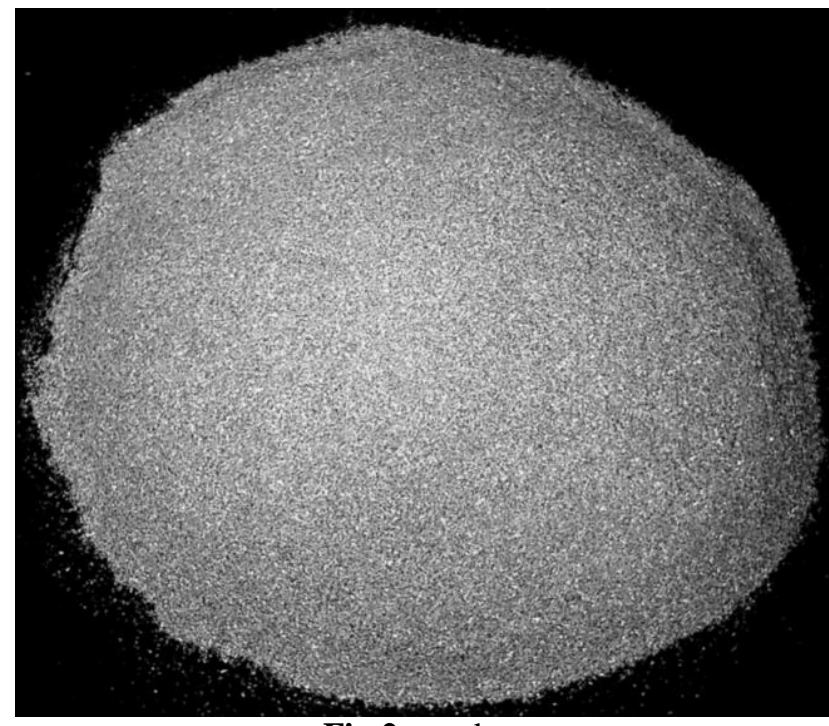

Fig 2 powders

\section{FABRICATION OF COMPOSITES}

All the composites were synthesized through stir casting technique, which is a proven and well established method for composite (MMC) making. Aluminium alloy was melted in an electric resistance furnace. A temperature of $760^{\circ} \mathrm{C}$, was maintained throughout the process. The melt was thoroughly degassed using helium, and gas jacket on melt was maintained throughout the process. A vortex was created at an rpm between 850 and 750 using a graphite impeller, preheated $\left(200^{\circ} \mathrm{C}\right)$ particles were added quickly (5-15 wt.\%) and continuously to the vortex, through a screen. At the end the particulate addition, composite was cast into a cast iron cylindrical mould, figure 3 shows the microstructure of composite material. Hot ingot was transferred to a furnace at $100^{\circ} \mathrm{C}$, and homogenized for 24 hrs.

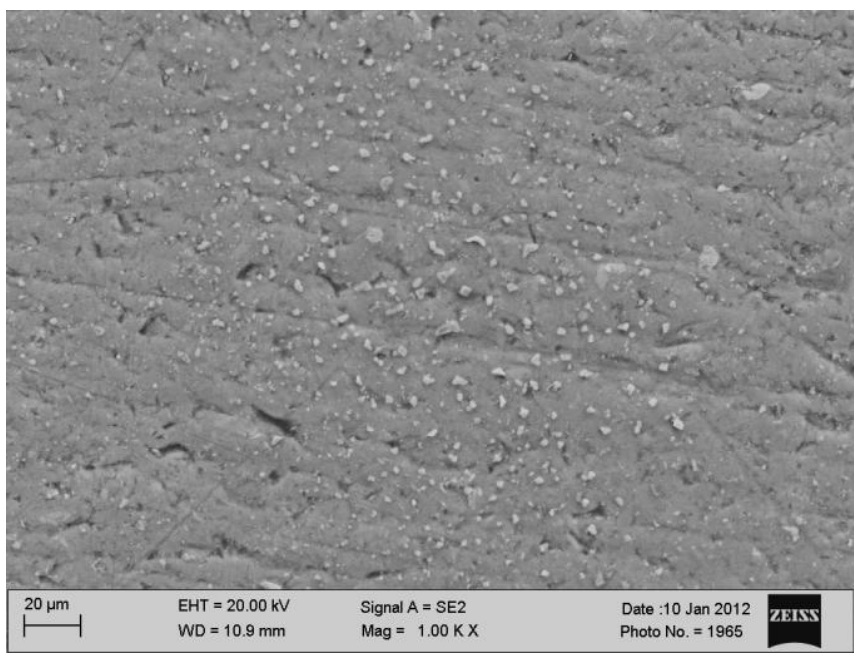

\section{MECHANICAL PROPERTIES}

The modulus of elasticity increased by 11 to $35 \%$ with the addition of 5 to $15 \%$ reinforcements. Presence of reinforcement restrict the mobility of the dislocation enhance the modulus to higher values. Similar behaviour 
was identified by many researchers. The increase in tensile elastic modulus with increased volume percent (3-10) of fly ash particulates which indicates that fly ash addition leads to improvement in the strength of the composites. The strength of the MMC is expected to increase by addition of solid ceramic particles due to the strengthening effects occurred in particulate reinforced composites. These effects include the transfer of stress from the matrix to the particulate, the interaction between individual dislocations and particulates, grain size strengthening mechanism due to a reduction in composite matrix grain size, and generation of a high dislocation density in the matrix of the composite as a result of the difference in thermal expansion between the metal matrix and particulates.

\begin{tabular}{|l|l|l|l|l|}
\hline \% Rein. & $\begin{array}{l}\text { Young's } \\
\text { Modulus } \\
\text { GPa }\end{array}$ & $\begin{array}{l}\text { Ultimate } \\
\text { Tensile } \\
\text { Strength } \\
\mathrm{MPa}\end{array}$ & $\begin{array}{l}\text { Yield } \\
\text { Strength, } \\
\mathrm{MPa}\end{array}$ & $\begin{array}{l}\% \\
\text { Elon. }\end{array}$ \\
\hline $\begin{array}{l}\text { Base A356 } \\
(0 \%)\end{array}$ & 69.23 & 289.3 & 186.21 & 28.14 \\
\hline 5 & 82.14 & 337.28 & 241.53 & 16.83 \\
\hline 10 & 90.7 & 357.87 & 282.22 & 14.05 \\
\hline 15 & 99.26 & 373.11 & 288.85 & 11.55 \\
\hline
\end{tabular}

\section{CONCLUSION}

1. Composites were fabricated by reinforcing Alloy Particulates in A356 matrix.

2. The decrease in particle size with increasing reinforcement content was due to increased casting time during processing.

3. Presence of reinforcement decreased the resistivity of the resultant composite

4. Composites exhibited improved hardness values compared to that of the alloy.

5. Increased reinforcement content enhanced the strength properties in terms of yield strength, ultimate tensile strength and modulus of elasticity

\section{SCOPE FOR FUTURE WORK}

Studies were made to find the damping properties in the present work, and found that properties were merely improving with the reinforcement content when compared to pure metals and alloy systems. However lot of research has to be done on the present scenario so that these materials can be best suited for naval and aerospace applications. The structure and properties of the reinforcements control the damping properties of the composites. Increase in elastic modulus and strength of the composites are reasoned to the strong interface that transfers and distributes the load from the matrix to the reinforcement. Further, the improved interface strength and better dispersion of the particles in the matrix can also be achieved by preheating the reinforcements and to improve the damping characteristics.

\section{REFERENCES}

[1]. V. Sethi, Effect of aging on abrasive wear resistance of silicon carbide particulate reinforced aluminum matrix composite, M.S thesis, 2007, pp.77-78.

[2]. E. Gikunoo, Effect of fly ash particles on the mechanical properties and microstructure of aluminium casting alloy A535, M.S thesis, 2004. p.97.

[3]. DJ. Lloyd, Aspects of fracture in particulate reinforced metal matrix composites Acta Metall Mater 1991, pp.59-71. [4]. Chawla C. Andres, J.W. Jones and J.E. Allison, Metall. Mater.Trans-A, 29A, 1998, pp.2843.

[5]. T.W.Clyne, An Introductory overview of MMC system, types and developments, in comprehensive composite materials, Vol-3; Metal matrix composites, Elsevier, 2000, pp. $1-26$

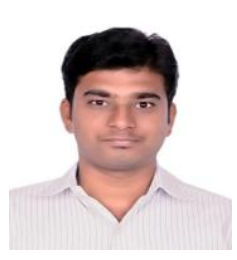

\section{BIOGRAPHIES}

Raja Surya Nukala is a final year M.Tech Mechanical Engineering student. $\mathrm{He}$ is pursuing his M.Tech from Loyala Institute of Technology and Management, Sattenapalli, Guntur Dt. Andhra Pradesh, India

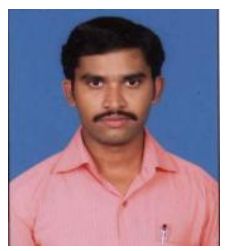

J Ajay is working as Assistant Professor in the Department of Mechanical Engineering at Loyala Institute of Technology and Management, Sattenapalli, Guntur Dt. Andhra Pradesh, India 